\title{
Incidence and characteristics of viral community- acquired pneumonia in adults
}

\author{
L C Jennings, ${ }^{1,2}$ T P Anderson, ${ }^{1} \mathrm{~K}$ A Beynon, ${ }^{1}$ A Chua, ${ }^{1}$ R T R Laing, ${ }^{3}$ A M Werno, ${ }^{1,2}$ \\ S A Young, ${ }^{1}$ S T Chambers, ${ }^{2}$ D R Murdoch ${ }^{1,2}$
}

${ }^{1}$ Canterbury Health

Laboratories, Christchurch, New Zealand; ${ }^{2}$ Department of

Pathology, Christchurch School of Medicine and Health Sciences, Christchurch, New Zealand; ${ }^{3}$ Canterbury Respiratory Research Group, University of Otago, Christchurch, New Zealand

Correspondence to: Dr L C Jennings, Canterbury Health Laboratories, P 0 Box 151, Christchurch, New Zealand; lance.jennings@cdhb.govt.nz

Received 21 November 2006 Accepted 22 May 2007 Published Online First

15 June 2007
ABSTRACT

Background: In adults, viral causes of communityacquired pneumonia (CAP) are poorly characterised. The aims of this study were to characterise the viral aetiology of CAP in adults by using an extensive array of viral diagnostic tests and to compare the characteristics of viral pneumonia with those of pneumococcal pneumonia. Methods: Adults admitted to Christchurch Hospital over a 1-year period with CAP were included in the study. Microbiological testing methods included blood and sputum cultures, urinary antigen testing for Streptococcus pneumoniae and Legionella pneumophila, antibody detection in paired sera and detection of respiratory viruses in nasopharyngeal swabs by immunofluorescence, culture and PCR.

Results: Of 304 patients with CAP, a viral diagnosis was made in 88 (29\%), with rhinoviruses and influenza A being the most common. Two or more pathogens were detected in 49 (16\%) patients, 45 of whom had mixed viral and bacterial infections. There were no reliable clinical predictors of viral pneumonia, although several variables were independently associated with some aetiologies. The presence of myalgia was associated with pneumonia caused by any respiratory virus (OR 3.62, 95\% $\mathrm{Cl} 1.29$ to 10.12) and influenza pneumonia (OR 190.72, 95\% Cl 3.68 to 9891.91). Mixed rhinovirus/pneumococcal infection was associated with severe disease.

Conclusions: Virus-associated CAP is common in adults. Polymicrobial infections involving bacterial and viral pathogens are frequent and may be associated with severe pneumonia.

Community-acquired pneumonia (CAP) is an important cause of morbidity and mortality throughout the world in all age groups. A clear understanding of likely pathogens is essential for the management of patients with CAP. ${ }^{1}$ The principal bacterial causes of CAP are well described, with Streptococcus pneumoniae being the most important pathogen in all age groups. Viruses - especially respiratory syncytial virus (RSV), influenza $A$ and $B$ viruses, parainfluenza viruses and adenovirusesare also recognised as important causes of CAP in children. ${ }^{2}{ }^{3}$ In adults, however, viral causes of CAP are less well characterised, and specific recommendations about the assessment and management of viral CAP are sparse. ${ }^{145}$ Most studies that have focused on viral CAP in adults have used a relatively limited range of viral diagnostic tools such as antibody detection only, thereby compromising the ability to determine the importance of viruses as pneumonia pathogens in adults. ${ }^{6}$

For several reasons, there has been renewed interest in viral lower respiratory tract infection in adults. The recent outbreaks of severe acute respiratory syndrome (SARS) ${ }^{7}$ and human cases of H5N1 influenza infection ${ }^{8}$ have focused attention on severe viral pneumonias. The discovery of human metapneumovirus has led to numerous studies seeking to clarify the role of this virus in human respiratory tract infections. ${ }^{9}$ Human bocavirus $^{10}$ and human coronavirus $\mathrm{NL}^{11} 3^{11}$ are more recently described viruses associated with respiratory tract infection in children. Mounting evidence now indicates that rhinovirus, previously considered to cause little more than the common cold, may frequently be associated with lower respiratory tract infections in children and adults. ${ }^{12}$ Developments in diagnostic tests (particularly nucleic acid amplification tests) have improved the ability to detect viruses in clinical samples and to characterise the epidemiology of respiratory virus infections. ${ }^{13-15}$ Importantly, these tests have highlighted how the role of viruses in CAP has been previously underestimated.

The primary aim of this study was to better characterise the viral aetiology of CAP in adults by using an extensive array of viral diagnostic tests, including PCR assays, for all common respiratory viruses. We also sought to compare the characteristics of viral pneumonia with those of pneumococcal pneumonia.

\section{METHODS}

\section{Subjects}

All patients aged $\geqslant 18$ years admitted to Christchurch Hospital (Christchurch, New Zealand) from July 1999 to July 2000 with a diagnosis of CAP were screened for inclusion in the study. Pneumonia was defined as an acute illness with radiographic pulmonary shadowing which was at least segmental or present in one lobe, and was neither pre-existing nor of other known cause. Patients were excluded when pneumonia was not the main reason for admission or was an expected terminal event or when the pneumonia was distal due to bronchial obstruction, bronchiectasis or known tuberculosis. Patients meeting the case definition were enrolled, and their characteristics and other clinical information were recorded in the study database as previously described. ${ }^{16}$ The study was approved by the Canterbury ethics committee and all subjects gave written informed consent.

\section{Samples}

At the time of enrolment, blood, urine, sputum and nasopharyngeal swab samples were collected. Convalescent sera were also collected 6 weeks after 
admission. Nasopharyngeal swabs (Medical Wire and Equipment, Corsham, UK) were placed in $3 \mathrm{ml}$ virus transport medium, forwarded to the laboratory and processed immediately or, if received outside working hours, stored at $4^{\circ} \mathrm{C}$ for up to $24 \mathrm{~h}$ before processing. These samples were vortexed and a $200 \mu \mathrm{l}$ aliquot was removed and frozen at $-70^{\circ} \mathrm{C}$ for future PCR testing. The remainder was used for direct antigen detection by immunofluorescence and enhanced cell culture. All serum samples were stored at $-20^{\circ} \mathrm{C}$ until serological testing.

\section{Immunofluorescence}

Each nasopharyngeal specimen was centrifuged at $700 \mathrm{~g}$ for $10 \mathrm{~min}$ at $4^{\circ} \mathrm{C}$ to sediment epithelial cells which were then spotted onto multiwell microscope slides, fixed and stained using Imagen reagents (DakoCytomation, UK).

\section{Viral culture}

Nasopharyngeal specimens were inoculated onto cell cultures of MDCK (Madin-Darby Canine Kidney), LLC-MK2 (Rhesus Monkey Kidney), Hep-2 (Human Epidermoid Carcinoma), A549 (Human Lung Carcinoma) and Hel (Human Epithelial Lung) in 48-well multiwell plates (Nunc) using enhanced cell culture with fluorescent antibody detection (ECCFA-48). Plates were incubated at $37^{\circ} \mathrm{C}$ in $5 \% \quad \mathrm{CO}_{2}$ and observed for the presence of a cytopathic effect at 48 and $72 \mathrm{~h}$. All cultures were screened after $72 \mathrm{~h}$ by direct immunofluorescence using Imagen reagents.

\section{Serology}

Acute and convalescent serum samples were analysed in parallel. Complement fixation tests (in-house) were performed to detect antibodies to influenza $\mathrm{A}$ and $\mathrm{B}$ viruses, adenovirus, RSV and parainfluenza viruses 1, 2 and 3; particle agglutination (Serodia Myco II, Fujirebio, Tokyo, Japan) for antibodies to Mycoplasma pneumoniae, immunofluorescence (MRL Diagnostics, Cypress, California, USA) for antibodies to Chlamydia pneumoniae and indirect immunofluorescence (MarDx Diagnostics, Scotch Plains, New Jersey, USA) for antibodies to Legionella spp.

\section{PCR}

Viral RNA was extracted from each nasopharyngeal swab specimen using the OIAamp Viral RNA kit (Oiagen, Hilden, Germany) following the manufacturer's instructions. The resultant RNA was eluted with $60 \mu$ l elution buffer and stored at $-80^{\circ} \mathrm{C}$ until testing. A negative control consisting of molecular grade water was included in every extraction run and PCR assay. Positive virus controls were obtained from known isolates cultured in the laboratory. Synthesis of cDNA was carried out at $37^{\circ} \mathrm{C}$ for $0.5 \mathrm{~h}$ using $5 \mu \mathrm{l}$ RNA template and an RT mixture $(5 \mu \mathrm{l})$ containing first strand buffer $(250 \mathrm{mM}$ Tris- $\mathrm{HCl}$ ( $\mathrm{pH} 8.3$ ), $375 \mathrm{mM} \mathrm{KCl}, 15 \mathrm{mM} \mathrm{MgCl}_{2}$ ) (Invitrogen, Grand Island, NY, USA), 420 U M-MLV (Moloney-Murine Leukemia Virus) reverse transcriptase (Invitrogen), 2 U RNAse OUT Recombinant Ribonuclease Inhibitor (Invitrogen), $150 \mu \mathrm{M}$ (each) dATP, dCTP, dGTP, and dTTP (Roche Diagnostics $\mathrm{GmbH}$, Mannheim, Germany) and $2.5 \mu \mathrm{M}$ random hexamer primers (Gibco BRL, Grand Island, NY, USA).

Eleven sets of oligonucleotide primers were selected for the amplification of highly conserved genetic sequences of RSV, influenza $\mathrm{A}$ and $\mathrm{B}$, parainfluenza viruses 1, 2 and 3, adenovirus, rhinovirus, coronavirus 229E and OC43 and metapneumovirus. ${ }^{14}$ Human metapneumovirus real-time PCR was performed as previously described. ${ }^{17}$ In-house conventional PCR assays were performed using a reaction mixture containing $1 \times$ PCR buffer without $\mathrm{MgCl}_{2}$ (Roche Diagnostics), 1.5-2.0 $\mathrm{mM} \mathrm{MgCl}_{2}$, a $100 \mu \mathrm{M}$ concentration of each deoxynucleoside triphosphate, a $0.5 \mu \mathrm{M}$ concentration of each primer and $1.25 \mathrm{U}$ Taq DNA polymerase (FastStart, Roche Diagnostics). Amplification was performed on the Mastercycler Gradient thermocycler (Eppendorf AG, Hamburg, Germany). PCR products were visualised by $2 \%$ agarose gel electrophoresis and ultraviolet illumination after ethidium bromide staining.

\section{Bacteriology}

Blood cultures were incubated aerobically and anaerobically using the BacT/ALERT blood culture system (bioMérieux, Durham, North Carolina, USA). Sputum was examined by Gram stain microscopy and cultured on sheep blood agar, chocolate agar, buffered charcoal yeast extract agar supplemented with $\alpha$-ketoglutarate and modified Wadowsky-Yee medium. Urine was tested for Legionella pneumophila serogroup 1 and $S$ pneumoniae antigens by the NOW Legionella and NOW Streptococcus pneumoniae urinary antigen tests (Binax, Portland, Maine, USA). ${ }^{18}$

\section{Definitions}

Viral infection was diagnosed when a respiratory virus was detected in nasopharyngeal samples by immunofluorescence, culture and/or PCR, and/or detection of a fourfold or greater rise in reciprocal antibody titres to a respiratory virus when testing paired serum samples. Pneumococcal infection was diagnosed when $S$ pneumoniae was isolated from blood and/or good quality purulent sputum $(>25$ leucocytes and $\leqslant 10$ squamous epithelial cells $/ \times 100$ field) samples, and/or detection of pneumococcal antigen in urine. Legionella infection was diagnosed by sputum culture, detection of Legionella antigen in urine and/or detection of a fourfold or greater rise in reciprocal antibody titres. Mycoplasma pneumoniae infection was diagnosed with reciprocal IgM antibody titres $\geqslant 160$, and Chlamydia pneumoniae infection was diagnosed with reciprocal antibody titres $\geqslant 512$. Infections with other bacterial pathogens were diagnosed by isolation from blood or good quality purulent sputum samples.

Disease severity was assessed by two methods: the CURBage score, ${ }^{19}$ with severe disease defined as a score $>2$; and the Pneumonia Severity Index (PSI), ${ }^{20}$ with severe disease defined as risk class IV and V.

\section{Statistical analysis}

Data were entered into a Microsoft Access database and analysed using Stata Version 8.2 (StataCorp, College Station, Texas, USA). Detailed analysis was performed on a restricted sample of 199 subjects who had a full battery of viral study results (immunofluorescence, culture, serology and PCR for all respiratory viruses) and who had blood cultures and pneumococcal urinary antigen testing results. Dichotomous variables were analysed with the $\chi^{2}$ test and continuous variables with the Wilcoxon rank sum test.

Logistic regression analysis was used to examine whether certain characteristics on admission were associated with specific microbial aetiologies. We were particularly interested to know whether any characteristics could be used as clinical markers of viral pneumonia. For this analysis, the presence or absence of specific infections (ie, any viral infection, influenza infection, rhinovirus infection and pneumococcal infection) 
Table 1 Viral pathogens identified in adults with community-acquired pneumonia

\begin{tabular}{lll}
\hline Virus & $\begin{array}{l}\text { All subjects* } \\
(\mathbf{n}=\mathbf{3 0 4 )}\end{array}$ & $\begin{array}{l}\text { Subjects with full array } \\
\text { of viral diagnostic tests* } \\
(\mathbf{n}=\mathbf{2 2 5})\end{array}$ \\
\hline Rhinovirus & $31(10)$ & $30(13)$ \\
Influenza A & $23(8)$ & $22(10)$ \\
Influenza B & $6(2)$ & $5(2)$ \\
RSV & $12(4)$ & $8(4)$ \\
Adenovirus & $11(4)$ & $10(4)$ \\
Parainfluenza & $6(2)$ & $2(1)$ \\
Coronavirus 229E & $4(1)$ & $3(1)$ \\
Coronavirus 0C43 & $2(1)$ & $2(1)$ \\
Metapneumovirus & $0(0)$ & $0(0)$ \\
Total & 95 & 82 \\
\hline
\end{tabular}

Data shown as number (\%).

*More than one virus was detected in some patients.

RSV, respiratory syncytial virus.

were the binary outcome variables in separate models. The models all included the following explanatory variables: age (in years), duration of symptoms (in days), influenza season (defined as May-October), presence of myalgia, presence of rigors, influenza vaccination within the past year, current smoking status (smoker vs non-smoker) and the presence of neutrophilia (defined as $>8 \times 10^{6} / 1$ ).

Logistic regression analysis was also used to assess independent associations with severe disease. Two models were constructed: the first model had severe disease as defined by the CURBage score as the outcome variable, while the second model had severe disease as defined by the PSI risk class as the outcome variable. The other variables included in both models were: age (years), male sex, presence of any comorbidity, current smoking status, radiographic presence of multilobe disease, presence of rhinovirus infection, presence of influenza infection, presence of pneumococcal infection, and influenza vaccination within the past year.

For all logistic regression analysis, likelihood ratio tests were used to compare models with and without interaction terms.

\section{RESULTS}

Of 304 patients (median age 70 years (range 18-99), 158 (52\%) men) admitted with CAP, an aetiological diagnosis could be established in 177 (58\%). A viral diagnosis was made in 88 (29\%) patients (table 1 ).

The most commonly identified non-viral pathogens were $S$ pneumoniae (93 (31\%)); Haemophilus influenzae (34 (11\%)); Legionella pneumophila (11 (4\%)); Mycoplasma pneumoniae (8 $(3 \%))$; and Staphylococcus aureus (7 (2\%)). Two or more pathogens were detected in 49 patients, 45 of whom had mixed viral and bacterial infections (table 2).

Of the different viral diagnostic tests, immunofluorescence detected 11 viruses, culture detected 32 viruses, serology detected 44 viruses and PCR detected 52 viruses. Interestingly, for influenza $A$ and $B$ viruses, adenovirus, parainfluenza virus and RSV, PCR contributed little extra to the diagnostic yield, with only 2 cases detected by PCR alone. On the other hand, PCR was the sole positive testing method for detection of rhinovirus and the coronaviruses. Owing to concerns about whether rhinovirus PCR positivity represented true infection or coincidental carriage, we tested a control group of patients who did not have respiratory or infectious diseases. These control patients were admitted to Christchurch Hospital at the same time as a subgroup of the cases with CAP, to whom they were
Table 2 Polymicrobial infections in 304 adults with communityacquired pneumonia

\begin{tabular}{|c|c|}
\hline Pathogens & Subjects (n) \\
\hline \multicolumn{2}{|l|}{ Mixed viral and bacterial pathogens: } \\
\hline \multicolumn{2}{|l|}{ Influenza A plus: } \\
\hline Streptococcus pneumoniae & 5 \\
\hline Streptococcus pneumoniae and Chlamydia pneumoniae & 1 \\
\hline Haemophilus influenzae & 1 \\
\hline Legionella pneumophila & 1 \\
\hline Pseudomonas aeruginosa & 1 \\
\hline \multicolumn{2}{|l|}{ Influenza B plus: } \\
\hline Staphylococcus aureus & 2 \\
\hline Streptococcus pneumoniae & 1 \\
\hline Legionella pneumophila & 1 \\
\hline \multicolumn{2}{|l|}{ Rhinovirus plus: } \\
\hline Streptococcus pneumoniae & 11 \\
\hline Haemophilus influenzae & 2 \\
\hline \multicolumn{2}{|l|}{ Respiratory syncytial virus plus: } \\
\hline Streptococcus pneumoniae & 4 \\
\hline Haemophilus influenzae & 1 \\
\hline Moraxella catarrhalis & 1 \\
\hline Pseudomonas aeruginosa & 1 \\
\hline \multicolumn{2}{|l|}{ Adenovirus plus: } \\
\hline Haemophilus influenzae & 2 \\
\hline Streptococcus pneumoniae & 1 \\
\hline \multicolumn{2}{|l|}{ Parainfluenza virus plus: } \\
\hline Streptococcus pneumoniae & 3 \\
\hline Haemophilus influenzae & 1 \\
\hline \multicolumn{2}{|l|}{ Coronavirus plus: } \\
\hline Streptococcus pneumoniae & 2 \\
\hline \multicolumn{2}{|l|}{ Multiple viral pathogens: } \\
\hline Influenza $\mathrm{A}$ and adenovirus & 1 \\
\hline Influenza A and coronavirus 229E & 1 \\
\hline Influenza A and rhinovirus and Haemophilus influenzae & 1 \\
\hline Influenza A and rhinovirus and Streptococcus pneumoniae & 1 \\
\hline Rhinovirus and respiratory syncytial virus & 1 \\
\hline $\begin{array}{l}\text { Respiratory syncytial virus and coronavirus } 229 \mathrm{E} \text { and } \\
\text { Haemophilus influenzae }\end{array}$ & 1 \\
\hline Adenovirus and coronavirus $229 \mathrm{E}$ & 1 \\
\hline Total & 49 \\
\hline
\end{tabular}

matched for age and sex. Unfortunately, nasopharyngeal swabs had not been collected from the control patients. However, throat swabs had been collected from both cases and control patients. We therefore tested throat swabs from 50 cases and from their matched controls by the rhinovirus PCR assay described previously. The cases were consecutive enrolments during a time of rhinovirus transmission. Throat swabs from 12 cases (24\%) tested positive for rhinovirus (including 10 of 13 who had positive nasopharyngeal swab samples), while only 1 $(2 \%)$ control throat swab sample tested positive for rhinovirus ( $p=0.003$, McNemar's test).

Figure 1 shows the monthly distribution of viral infections; the influenza season in New Zealand usually occurs in May to October. Characteristics of pneumonia associated with specific respiratory viruses are shown in table 3 .

Of the 88 patients with documented viral infections, 4 were admitted to the intensive care unit, 5 died during hospital admission and 1 died between discharge and 6-week follow-up.

Detailed analysis was performed on 199 subjects who had the full battery of results for all viral studies, blood cultures and pneumococcal urinary antigen testing. The median age of this group was 68 years (range 19-95) and 103 (52\%) were men. Of these patients, $67(34 \%)$ had a viral infection. The following 

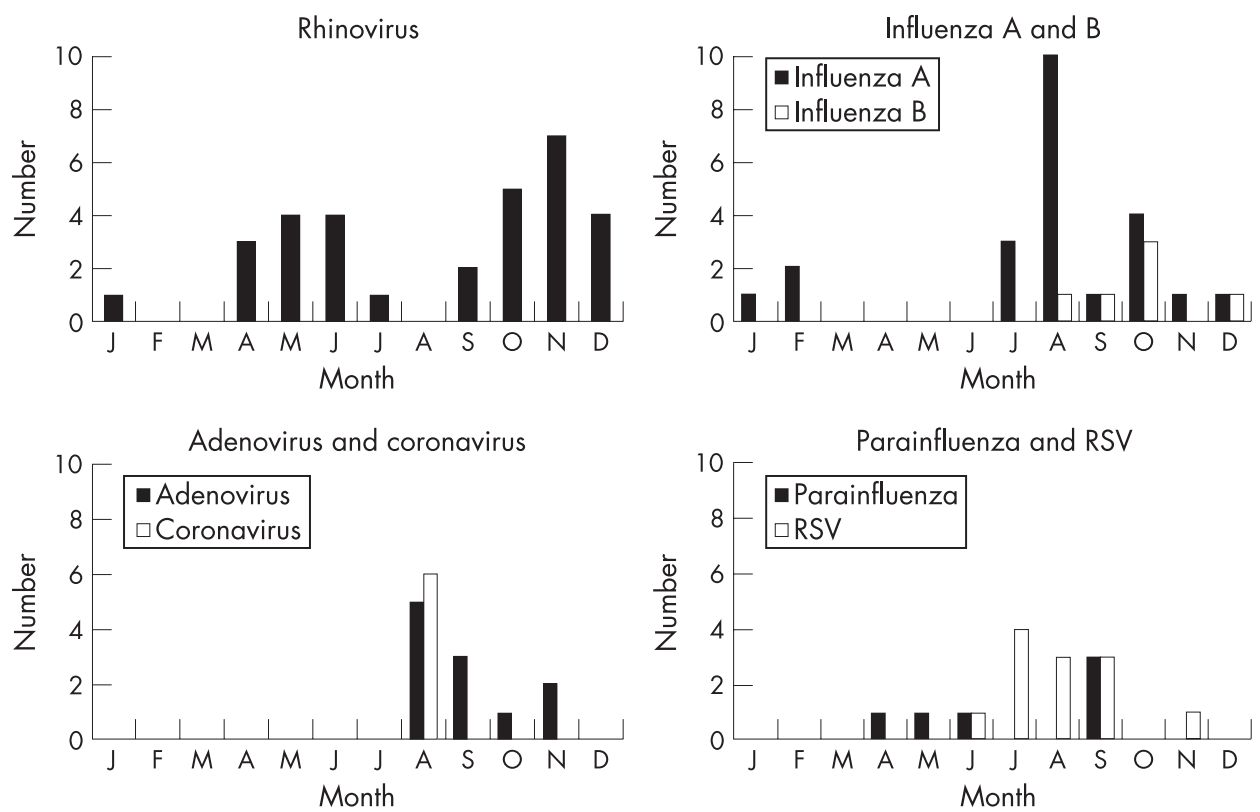

Figure 1 Monthly distribution of cases of virus-associated community-acquired pneumonia. RSV, respiratory syncytial virus.

Table 3 Characteristics of patients with community-acquired pneumonia associated with specific respiratory viruses

\begin{tabular}{|c|c|c|c|c|c|c|c|}
\hline & \multicolumn{7}{|c|}{ Aetiological agent } \\
\hline & $\begin{array}{l}\text { Rhinovirus } \\
(\mathrm{n}=31)\end{array}$ & $\begin{array}{l}\text { Influenza A } \\
(\mathrm{n}=23)\end{array}$ & $\begin{array}{l}\text { Influenza B } \\
(\mathrm{n}=6)\end{array}$ & $\begin{array}{l}\text { RSV } \\
(n=12)\end{array}$ & $\begin{array}{l}\text { Adenovirus } \\
(\mathrm{n}=11)\end{array}$ & $\begin{array}{l}\text { Parainfluenza virus } \\
(\mathrm{n}=6)\end{array}$ & $\begin{array}{l}\text { Coronavirus } \\
(n=6)\end{array}$ \\
\hline $\begin{array}{l}\text { Age (years) } \\
\text { (median (IQR)) }\end{array}$ & $66(42-78)$ & $66(55-76)$ & $72(68-83)$ & $79(70-81)$ & $51(30-71)$ & $81(73-86)$ & $71(55-78)$ \\
\hline $\begin{array}{l}\text { Duration symptoms (days) } \\
\text { (median (IQR)) }\end{array}$ & $7(3-7)$ & $7(3-21)$ & $6(4-14)$ & $6(4-18)$ & $3(2-7)$ & $6(4-7)$ & $6(4-14)$ \\
\hline Sputum & 23/31 (74) & $16 / 22(73)$ & $4 / 6(67)$ & $10 / 12(83)$ & 8/11 (73) & $2 / 5(40)$ & $4 / 6(67)$ \\
\hline Pleuritic pain & $18 / 31(58)$ & $8 / 23(35)$ & $3 / 6(50)$ & $4 / 12(33)$ & $6 / 10(60)$ & $2 / 5(40)$ & $4 / 6(67)$ \\
\hline Rigors & $14 / 29(48)$ & $5 / 11(46)$ & $1 / 3(33)$ & $2 / 8(25)$ & $1 / 4(25)$ & $2 / 3(67)$ & $2 / 2(100)$ \\
\hline Lethargy & $26 / 30(87)$ & $15 / 15(100)$ & $4 / 4(100)$ & $7 / 9(78)$ & $5 / 6(83)$ & $2 / 2(100)$ & $3 / 3(100)$ \\
\hline Anorexia & $23 / 30(77)$ & $13 / 14(93)$ & $3 / 3(100)$ & $6 / 9(67)$ & $6 / 6(100)$ & $0 / 2(0)$ & $2 / 2(100)$ \\
\hline Diarrhoea & $5 / 30(17)$ & $5 / 12(42)$ & $3 / 4(75)$ & $4 / 8(50)$ & $2 / 6(33)$ & $0 / 2(0)$ & - \\
\hline Asthma & $8 / 31(26)$ & $3 / 23(13)$ & $0 / 6(0)$ & $1 / 12(8)$ & $3 / 11$ (27) & $0 / 6(0)$ & $1 / 6(17)$ \\
\hline Cardiac failure & $2 / 31(7)$ & $3 / 23(13)$ & $1 / 6(17)$ & $5 / 12(42)$ & $3 / 11$ (27) & $2 / 6(33)$ & $0 / 6(0)$ \\
\hline Diabetes & $3 / 31(10)$ & $3 / 23(13)$ & $1 / 6(17)$ & $6 / 12(50)$ & $1 / 11(9)$ & $0 / 6(0)$ & $1 / 6(17)$ \\
\hline Cerebrovascular disease & $4 / 31$ (13) & $3 / 23(13)$ & $0 / 6(0)$ & $5 / 12(42)$ & $1 / 11(9)$ & $2 / 6(33)$ & $0 / 6(0)$ \\
\hline Renal disease & $1 / 31(3)$ & $1 / 23(4)$ & $1 / 6(17)$ & $1 / 12(8)$ & $1 / 11(9)$ & $0 / 6(0)$ & $0 / 6(0)$ \\
\hline Current smoker & $7 / 31(23)$ & $7 / 23(30)$ & $1 / 6(17)$ & $1 / 12(8)$ & $4 / 11(36)$ & $1 / 6(17)$ & $0 / 6(0)$ \\
\hline $\begin{array}{l}\text { Influenza vaccine within } \\
1 \text { year }\end{array}$ & $16 / 31(52)$ & $7 / 23(30)$ & $2 / 5(40)$ & $8 / 12(67)$ & $5 / 11(46)$ & $5 / 6(83)$ & $2 / 6(33)$ \\
\hline CURBage $>2$ & $7 / 31(23)$ & $2 / 23(9)$ & $1 / 6(17)$ & $4 / 12(33)$ & $3 / 11(27)$ & $3 / 6(50)$ & $2 / 6(33)$ \\
\hline PSI class IV and V & $12 / 31$ (39) & $15 / 23(65)$ & $3 / 6(50)$ & $9 / 12(75)$ & $4 / 11(36)$ & $5 / 6(83)$ & $3 / 6(50)$ \\
\hline Multilobe disease & $13 / 31(42)$ & $13 / 23(57)$ & $4 / 6(67)$ & $2 / 12(17)$ & $3 / 11(27)$ & $4 / 6(67)$ & 2/6 (33) \\
\hline Neutrophils $>8 \times 10^{6} / 1$ & $29 / 31(94)$ & $17 / 23(74)$ & $5 / 6(83)$ & $8 / 12(67)$ & $10 / 11(91)$ & $6 / 6(100)$ & $5 / 6(83)$ \\
\hline
\end{tabular}

Data are shown as number (\%) unless otherwise specified.

COPD, chronic obstructive pulmonary disease; PSI, Pneumonia Severity Index. 
Table 4 Associations with viral and pneumococcal pneumonia on multivariate analysis

\begin{tabular}{|c|c|c|c|}
\hline Outcome & Variable & OR $(95 \% \mathrm{CI})$ & p Value \\
\hline \multirow[t]{3}{*}{ Infection with any virus } & Myalgia & $3.62(1.29$ to 10.12$)$ & 0.01 \\
\hline & Influenza vaccine (May-October) & $0.11(0.02$ to 0.61$)$ & 0.01 \\
\hline & Influenza vaccine (November-April) & $1.21(0.25$ to 5.95$)$ & 0.81 \\
\hline \multirow[t]{5}{*}{ Influenza infection } & Age (per 1 year increase) & $1.20(1.04$ to 1.38$)$ & 0.01 \\
\hline & Infection in May-October & $57.40(1.03$ to 3209.38$)$ & 0.05 \\
\hline & Influenza vaccine & $0.001(<0.0001$ to 0.33$)$ & 0.02 \\
\hline & Myalgia & 190.72 (3.68 to 9891.91$)$ & 0.009 \\
\hline & Neutrophilia & $0.03(0.001$ to 0.60$)$ & 0.02 \\
\hline \multirow[t]{2}{*}{ Rhinovirus infection } & Infection in May-October & $0.39(0.14$ to 1.07$)$ & 0.07 \\
\hline & Neutrophilia & 9.93 (1.19 to 82.83$)$ & 0.03 \\
\hline \multirow[t]{2}{*}{ Pneumococcal infection } & Rigors & $2.61(1.06$ to 6.44$)$ & 0.04 \\
\hline & Current smoking & 4.04 (1.33 to 12.28$)$ & 0.01 \\
\hline
\end{tabular}

were statistically significant differences between monomicrobial viral and monomicrobial pneumococcal pneumonia on univariable analysis. Compared with patients with pneumococcal pneumonia, diabetes was more common ( $11 \%$ vs $0 \%, \mathrm{p}=0.02)$, severe disease (CURBage score $>2$ ) was less common ( $9 \%$ vs $28 \%, p=0.02)$ and duration of symptoms before admission was longer (median 7 vs 4 days, $p=0.04$ ) in patients with pneumonia associated with any respiratory virus. Myalgia $(80 \%$ vs $27 \%, p=0.02)$ and diabetes (13\% vs $0 \%, p=0.02)$ were more common and neutrophilia (neutrophil count $\left.>8 \times 10^{6} / 1\right) \quad(60 \%$ vs $85 \%, p=0.04)$ and severe disease (CURBage score $>2$ ) ( $0 \%$ vs $28 \%, p=0.02)$ were less common in patients with influenza than in those with pneumococcal pneumonia.

Table 4 shows the significant associations with viral and pneumococcal pneumonia on multivariate analysis. The inclusion of an interaction term between influenza season and influenza vaccination significantly improved the model for pneumonia associated with any viral infection. Of particular note are the associations of myalgia with influenza infection, neutrophilia with rhinovirus infection, and rigors and smoking with pneumococcal infection.

Table 5 shows the significant independent associations with disease severity as assessed by both CURBage score and PSI risk class. The inclusion of interaction terms between rhinovirus infection and pneumococcal infection significantly improved both models. Increasing age, male sex and mixed rhinovirus/ pneumococcal infection were independently associated with severe disease as assessed with both severity assessment tools.

\section{DISCUSSION}

This is one of few studies to use such a comprehensive battery of viral diagnostic tests in order to detect respiratory virus infection in adults with CAP. Our findings indicate that about one-third of adults admitted to hospital with CAP (at least half of those with an identifiable pathogen) have evidence of infection with one or more respiratory viruses. Other studies that have not used nucleic acid amplification assays have typically reported that $5-20 \%$ of adult cases of CAP have a viral aetiology. ${ }^{21}$ In a similar study to our own, respiratory virus infections were detected in 15 (14\%) of 105 adults with CAP by conventional diagnostic methods, but this increased to 59 (56\%) when real-time PCR was used. ${ }^{15}$ Similarly, in another study of 198 adults with CAP, respiratory viruses were identified in 46 patients $(23 \%){ }^{22}$ In that study, serology detected 6 viruses, immunofluorescence 8 viruses, culture detected 12 viruses and PCR detected 45 viruses.

Although rhinoviruses were the most commonly identified virus in our patients, their role in pneumonia is controversial. Despite optimal replication occurring at $33-35^{\circ} \mathrm{C}$, thereby restricting growth at core body temperature, increasing evidence links rhinoviruses to infection of the lower respiratory tract. Rhinovirus infection has been associated with pneumonia and bronchiolitis in young children and exacerbations of pre-existing airways diseases such as asthma, chronic obstructive pulmonary disease and cystic fibrosis. ${ }^{12}$ Outbreaks of severe respiratory disease (including pneumonia) in elderly nursing home residents have been associated with rhinovirus. ${ }^{23}{ }^{24}$ We detected rhinoviruses in samples from $>10 \%$ of adults in our study. This

Table 5 Independent associations with disease severity

\begin{tabular}{lllc}
\hline Outcome & Variable & OR (95\% CI) & p Value \\
\hline $\begin{array}{l}\text { Severe disease } \\
\text { (CURBage score) }\end{array}$ & Age (per 1 year increase) & $1.09(1.05$ to 1.14) & $<0.001$ \\
& Male sex & $3.26(1.36$ to 7.82$)$ & 0.008 \\
& $\begin{array}{l}\text { Rhinovirus infection (with } \\
\text { concomitant pneumococcal infection) }\end{array}$ & 9.95 (1.31 to 75.34) & 0.03 \\
& $\begin{array}{l}\text { Rhinovirus infection (without } \\
\text { concomitant pneumococcal infection) }\end{array}$ & 0.18 (0.02 to 1.81) & 0.15 \\
Severe disease & Age (per 1 year increase) & $1.17(1.11$ to 1.23$)$ & $<0.001$ \\
(PSI risk class) & Male sex & $2.50(1.04$ to 5.98) & 0.04 \\
& Current smoker & $3.28(1.03$ to 10.45) & 0.05 \\
& $\begin{array}{l}\text { Rhinovirus infection (with } \\
\text { concomitant pneumococcal infection) }\end{array}$ & $11.52(1.09$ to 121.89) & 0.04 \\
& $\begin{array}{l}\text { Rhinovirus infection (without } \\
\text { concomitant pneumococcal infection) }\end{array}$ & $0.18(0.04$ to 0.87) & 0.03 \\
\hline
\end{tabular}

PSI, Pneumonia Severity Index. 
compares with a detection rate of $17 \%$ in adults admitted to hospital with CAP in the Netherlands, ${ }^{15} 4 \%$ in adults hospitalised with CAP in Spain $^{22}$ and $33 \%$ in adults presenting to primary care in the UK with lower respiratory tract infections. ${ }^{25}$ A limitation of other studies is the lack of a control group and the uncertainty about the prevalence of asymptomatic rhinovirus infection. For example, rhinovirus RNA has been detected in upper respiratory samples from $3 \%$ of asymptomatic elderly adults. ${ }^{26}$ Although our control group was suboptimal because nasopharyngeal swabs had not been collected from them, we believe the concordance of rhinovirus PCR results between throat and nasopharyngeal swabs for the patients with CAP and the lack of positive results in throat swabs from controls provides circumstantial evidence that detection of rhinovirus represents true infection in our sample. Interestingly, a recent longitudinal study in healthy children showed that picornavirus infections (diagnosed by PCR) were usually associated with clinical illness. ${ }^{27}$

It remains unclear whether viruses alone cause pneumonia, or whether they act in conjunction with other respiratory pathogens. Mounting evidence suggests that many respiratory viruses are capable of invading and replicating in the lower respiratory tract mucosa. ${ }^{28} 29$ Respiratory viruses are also now recognised as important causes of severe lower respiratory tract infections in immunocompromised patients. ${ }^{30}$ Alternatively, respiratory viral infection may predispose to bacterial pneumonia. ${ }^{31}$ Bacterial pneumonia is a well recognised complication of influenza, ${ }^{32}$ and pneumococcal vaccination has been associated with reduced virus-associated pneumonia in children. ${ }^{33}$ Adherence of $S$ pneumoniae to human tracheal epithelial cells is higher in the presence of rhinovirus, ${ }^{34}$ and there is ample evidence that influenza virus infection predisposes to adherence, invasion and induction of disease by pneumococcus. ${ }^{32}$ Consistent with the coinfection model, there was a relatively high rate of documented polymicrobial infection in our study, and this finding has been described by others. ${ }^{6} 15223536$ Approximately half of the patients in our study with viral infections also had a documented infection with at least one bacterial pathogen. Interestingly, mixed rhinovirus/pneumococcal infection was independently associated with both measures of severe disease. An association between polymicrobial infection involving viruses and severe pneumonia has been noted by others ${ }^{15}$ but, to our knowledge, the association between mixed rhinovirus/pneumococcal infection and severe pneumonia has not been previously reported. This observation needs to be confirmed by other studies.

We identified no reliable clinical predictors of viral pneumonia, although several variables were associated with some aetiologies on multivariate analysis. Influenza vaccination was associated with reduced odds of influenza pneumonia and of any viral pneumonia during May-October. The presence of myalgia was associated with viral pneumonia and, in particular, influenza pneumonia. Interestingly, neutrophilia was associated with reduced odds of influenza pneumonia but increased odds of having rhinovirus infection. The reason for the latter association is unclear, although it is possible that this is a result of infection with a bacterial co-pathogen such as $S$ pneumoniae. One-third of subjects with rhinovirus infections also had documented $S$ pneumoniae infection. In comparison with the viral-associated pneumonias, the presence of rigors and current smoking were associated with pneumococcal pneumonia.

An important limitation of this study, as with all similar studies, is the sizeable minority of patients for whom a microbiological aetiology cannot be determined. Although this proportion is smaller than many previous studies because of the use of improved diagnostics, we are undoubtedly still underestimating the prevalence of many aetiologies including the respiratory viruses. It is likely that the importance of both viral pneumonia and mixed viral/bacterial pneumonia is greater than we have estimated. This will only be confirmed with further improvement in diagnostic testing methods.

The management of CAP in adults has traditionally focused little on potential viral causes. This situation is largely due to the lack of specific antiviral agents and the impression that viral pathogens play a relatively minor role in adult pneumonia. Increasing awareness that adult CAP is commonly associated with viral infections, the potential impact of viral vaccines and the increasing availability of antiviral chemotherapeutic agents should direct researchers and clinicians to focus more on the role of respiratory viruses in adult CAP. Several anti-influenza agents, including oseltamivir and zanamivir, are now available, ${ }^{37}$ and agents against other viruses (such as pleconaril against rhinoviruses) are undergoing clinical evaluation. ${ }^{38} 39$

In summary, our findings add further evidence that viralassociated CAP is common in adults. Furthermore, polymicrobial infections involving bacterial and viral pathogens were common, and mixed rhinovirus/pneumococcal infection appears to be associated with severe pneumonia. Despite recent improvements in diagnostic tests, no aetiological agent can be identified in a large proportion of adults admitted to hospital with CAP, and it is likely that the prevalence of both viral and mixed bacterial-viral infection is even higher than currently estimated. Further research should focus on better characterising the viral burden in adult CAP and the interaction between bacterial and viral pathogens.

Acknowledgements: The authors thank Anton Russell and other staff of the Microbiology Department, Canterbury Health Laboratories, other members of the Christchurch Community-Acquired Pneumonia Study research team and Binax Inc for donating the urinary antigen tests.

Funding: Health Research Council of New Zealand, the Canterbury Respiratory Research Trust and Canterbury District Health Board.

Competing interests: None.

\section{REFERENCES}

1. Mandell LA, Bartlett JG, Dowell SF, et al. Update of practice guidelines for the management of community-acquired pneumonia in immunocompetent adults. Clin Infect Dis 2003;37:1405-32.

2. Juvén T, Mertsola $\mathrm{J}$, Waris $\mathrm{M}$, et al. Etiology of community-acquired pneumonia in 254 hospitalized children. Pediatr Infect Dis J 2000;19:292-8.

3. Tsolia MN, Psarras S, Bossios A, et al. Etiology of community-acquired pneumonia in hospitalized school-age children: evidence for high prevalence of viral infections. Clin Infect Dis 2004;39:681-6.

4. Niederman MS, Mandell LA, Anzueto A, et al. Guidelines for the management of adults with community-acquired pneumonia: diagnosis, assessment of severity, antimicrobial therapy, and prevention. Am J Respir Crit Care Med 2001;163:1730-54

5. Woodhead M, Blasi F, Ewig S, et al. Guidelines for the management of adult lower respiratory tract infections. Eur Respir J 2005;26:1138-80.

6. de Roux A, Marcos MA, Garcia E, et al. Viral community-acquired pneumonia in nonimmunocompromised adults. Chest 2004;125:1343-51.

7. Peiris JSM, Yuen KY, Osterhaus A, et al. Current concepts: the severe acute respiratory syndrome. N Engl J Med 2003;349:2431-41.

8. Writing Committee of the World Health Organization Consultation on Human Influenza AH. Avian influenza A (H5N1) infection in humans. N Engl J Med 2005;353:1374-85.

9. Crowe JE. Human metapneumovirus as a major cause of human respiratory tract disease. Pediatr Infect Dis J 2004;23:S215-21.

10. Arnold JC, Singh KK, Spector SA, et al. Human bocavirus: prevalence and clinical spectrum at a children's hospital. Clin Infect Dis 2006;43:283-8.

11. van der Hoek L, Pyrc K, Berkhout B. Human coronavirus NL63, a new respiratory virus. FEMS Microbiol Rev 2006;30:760-73.

12. Hayden FG. Rhinovirus and the lower respiratory tract. Rev Med Virol 2004;14:1731.

13. Murdoch DR. Molecular genetic methods in the diagnosis of lower respiratory tract infections. APMIS 2004;112:713-27. 
14. Jennings LC, Anderson TP, Werno AM, et al. Viral etiology of acute respiratory tract infections in children presenting to hospital: role of polymerase chain reaction and demonstration of multiple infections. Pediatr Infect Dis J 2004;23:10037.

15. Templeton KE, Scheltinga SA, van den Eeden WCJFM, et al. Improved diagnosis of the etiology of community-acquired pneumonia with real-time polymerase chain reaction. Clin Infect Dis 2005; 41:345-51.

16. Laing R, Slater W, Coles C, et al. Community-acquired pneumonia in Christchurch and Waikato 1999-2000: microbiology and epidemiology. NZ Med J 2001;114:48892.

17. Werno AM, Anderson TP, Jennings LC, et al. Human metapneumovirus in children with bronchiolitis or pneumonia in New Zealand. J Paediatr Child Health 2004; 40:549-51.

18. Murdoch DR, Laing RTR, Mills GD, et al. Evaluation of a rapid immunochromatographic test for detection of Streptococcus pneumoniae antigen in urine samples from adults with community-acquired pneumonia. J Clin Microbiol 2001;39:3495-8.

19. Lim WS, van der Eerden MM, Laing R, et al. Defining community acquired pneumonia severity on presentation to hospital: an international derivation and validation study. Thorax 2003;58:377-82.

20. Fine MJ, Auble TE, Yealy DM, et al. A prediction rule to identify low-risk patients with community-acquired pneumonia. N Engl J Med 1997;336:243-50.

21. File TM. Community-acquired pneumonia. Lancet 2003;362:1991-2001.

22. Marcos MA, Camps M, Pumarola T, et al. The role of viruses in the aetiology of community-acquired pneumonia in adults. Antiviral Ther 2006;11:351-9.

23. Wald TG, Shult $P$, Krause $P$, et al. A rhinovirus outbreak among residents of a longterm care facility. Ann Intern Med 1995;123:588-93.

24. Hicks LA, Shepard CW, Britz PH, et al. Two outbreaks of severe respiratory disease in nursing homes associated with rhinovirus. J Am Geriatr Soc 2006;54:284-9.

25. Creer DD, Dilworth JP, Gillespie SH, et al. Aetiological role of viral and bacterial infections in acute adult lower respiratory tract infection (LRTI) in primary care. Thorax 2006;61:75-9.
26. Nicholson KG, Kent J, Hammersley V, et al. Risk factors for lower respiratory complications of rhinovirus infections in elderly people living in the community: prospective cohort study. BMJ 1996;313:1119-23.

27. Winther B, Hayden FG, Hendley JO. Picornavirus infections in children diagnosed by RT-PCR during longitudinal surveillance with weekly sampling: association with symptomatic illness and effect of season. J Med Virol 2006;78:644-50.

28. Panuska JR, Cirino NM, Midulla F, et al. Productive infection of isolated human alveolar macrophages by respiratory syncytial virus. J Clin Invest 1990;86:113-9.

29. Papadopoulos NG, Bates PJ, Bardin PG, et al. Rhinoviruses infect the lower airways. J Infect Dis 2000;181:1875-84.

30. van Elden LJR, van Kraaij MGJ, Nijhuis M, et al. Polymerase chain reaction is more sensitive than viral culture and antigen testing for the detection of respiratory viruses in adults with hematological cancer and pneumonia. Clin Infect Dis 2001;34:177-83.

31. Bakaletz LO. Viral potentiation of bacterial superinfection of the respiratory tract. Trends Microbiol 1995;3:110-4.

32. McCullers JA. Insights into the interaction between influenza virus and pneumococcus. Clin Microbiol Rev 2006;19:571-82.

33. Madhi SA, Klugman KP, The Vaccine Trialist Group. A role for Streptococcus pneumoniae in virus-associated pneumonia. Nat Med 2004;10:811-3.

34. Ishizuka S, Yamaya M, Suzuki T, et al. Effects of rhinovirus infection on the adherence of Streptococcus pneumoniae to cultured human airway epithelial cells. $J$ Infect Dis 2003;188:1928-39.

35. de Roux A, Ewig S, García E, et al. Mixed community-acquired pneumonia in hospitalised patients. Eur Respir J 2006;27:795-800.

36. Gutiérrez F, Masiá M, Rodríguez JC, et al. Community-acquired pneumonia of mixed etiology: prevalence, clinical characteristics, and outcome. Eur J Clin Microbiol Infect Dis 2005;24:377-83.

37. Hayden FG. Antivirals for influenza: historical perspectives and lessons learned. Antiviral Res 2006:71:372-8.

38. Pevear DC, Hayden FG, Demenczuk TM, et al. Relationship of pleconaril susceptibility and clinical outcomes in treatment of common colds caused by rhinoviruses. Antimicrob Agents Chemother 2005:49:4492-9.

39. Patick AK. Rhinovirus chemotherapy. Antiviral Res 2006;71:391-6.

\section{Lung alert}

\section{Passive smoking exposure is associated with an increased risk of COPD}

More than $15 \%$ of patients with chronic obstructive pulmonary disease (COPD) are never smokers. This study attempted to correlate passive smoking exposure with the risk of developing COPD in a South Chinese population.

Participants were drawn from the Biobank cohort of over 100000 Guangzhou residents. The study group comprised 6497 never smokers aged over 50 with valid recently recorded spirometric parameters; those with chronic diseases were excluded. Passive smoking was self-reported as exposure during childhood, in the home and in the workplace. Further categorisation included density (eg, number of smokers in a household) and duration of exposure.

More than half of the never smokers reported exposure to passive smoking; $28 \%$ reported exposure of $>5$ years either at home or at work. COPD (defined according to GOLD guidelines) was associated with duration (but not density) of exposure. It was more common among those with $>5$ years' exposure at home and at work than those who had $<2$ years' exposure. COPD was more common among men, who formed only $10.4 \%$ of the study group (men are underrepresented in the Biobank cohort for cultural reasons).

The study concludes that there is a significant but small association between passive smoking exposure and the risk of developing COPD, with approximately $11.6 \%$ of all deaths in China among never smokers attributable to COPD. It has been estimated that only one-third of people in China believe that passive smoking is harmful to health.

- Yin P, Jiang CQ, Cheng KK, et al. Passive smoking exposure and the risk of COPD amongst adults in China: the Guangzhou Biobank Cohort study. Lancet 2007; $370: 751-7$

\section{A Nataraja}

Correspondence to: A Nataraja, SpR Respiratory Medicine, Northampton General Hospital, Northampton, UK; anjalinataraja@ hotmail.com 